\title{
A IGREJA POSITIVISTA DA RUA BENJAMIN CONSTANT
}

\author{
THE POSITIVIST CHURCH ON BENJAMIN \\ CONSTANT STREET
}

Muito embora o positivismo seja uma escola filosófica onde domina o cientificismo, ela é também responsável por uma postura profundamente religiosa. Isto porque, a partir do encontro de Auguste Comte com Clotilde de Vaux, ou seja, após aquilo que ele chamou de sua "regeneração moral", desenvolveram-se em seu pensamento os elementos utópicos. De filosofia da história, o positivismo comtiano transformou-se em religião da humanidade, com sua teologia, seus rituais, sua hagiografia. O cívico tornou-se religioso: os santos da nova religião era os grandes homens da humanidade, os rituais eram festas cívicas, a teologia era sua filosofia e sua política.

A mulher adquiriu importância crucial, sempre representada pela figura de Clotilde de Vaux, que, por determinação do mestre, deveria estar presente em todos os templos positivistas. A Virgem católica, alegoria da Igreja, tornou-se no positivismo a VirgemMãe, alegoria da humanidade. O novo culto foi minuciosamente descrito. Há um calendário positivista, com 13 meses, cada mês com quatro semanas, cada semana com sete dias. Cada mês e cada dia são dedicados a uma figura considerada importante na evolução da humanidade. O templo positivista deveria exibir a estátua da humanidade em posição central. Haveria também altares laterais, um deles dedicado às santas mulheres.

No Brasil, a junção da doutrina comtista com a visão estratégica dos ortodoxos (chefiados por Miguel Lemos e Teixeira Mendes) fez desses positivistas - que rapidamente entraram em conflito com a corrente para quem esta religiosidade era abominável — os principais manipuladores dos símbolos da República. O Brasil se lhes apresentava como às portas de grandes transformações, talvez mesmo de verdadeiro salto na seqüência das fases evolutivas previstas pelo pensamento positivista. Daí se terem lançado à doutrinação política com convicção e energia de apóstolos, daí, talvez, a urgência e necessidade da construção do templo.

Se a ação tinha de se basear no convencimento, impunha-se o uso dos símbolos. Em primeiro lugar, sem dúvida, a palavra escrita e falada. Dela fizeram uso abundante em livros, jornais, publicações da Igreja (que se contam às centenas), conferências públicas. Era sua principal arma de convencimento dos setores médios. Mas empregaram também o simbolismo das imagens e dos rituais, tendo em vista especialmente dois públicos estratégicos, as mulheres e o proletariado, menos afetos, no Brasil 
daquela época, à palavra escrita. Atingir esses dois públicos, convencê-los da verdade da doutrina, era condição indispensável para o êxito da tarefa que se impunham. A briga pelas imagens adquirira importância central.

O Templo Positivista do Rio de Janeiro, cuja pedra inaugural foi lançada no final do século XIX, conserva até hoje todas as marcas do imaginário positivista do início deste século. E até hoje, em sua beleza um pouco fanada, quem o visita pode perceber alguns traços do pensamento positivista. Esperamos que nas fotografias de Nelson Monteiro, apresentadas nas próximas páginas, algumas de suas características mais importantes, algumas de suas imagens mais fortes, fiquem claras para nossos leitores. 

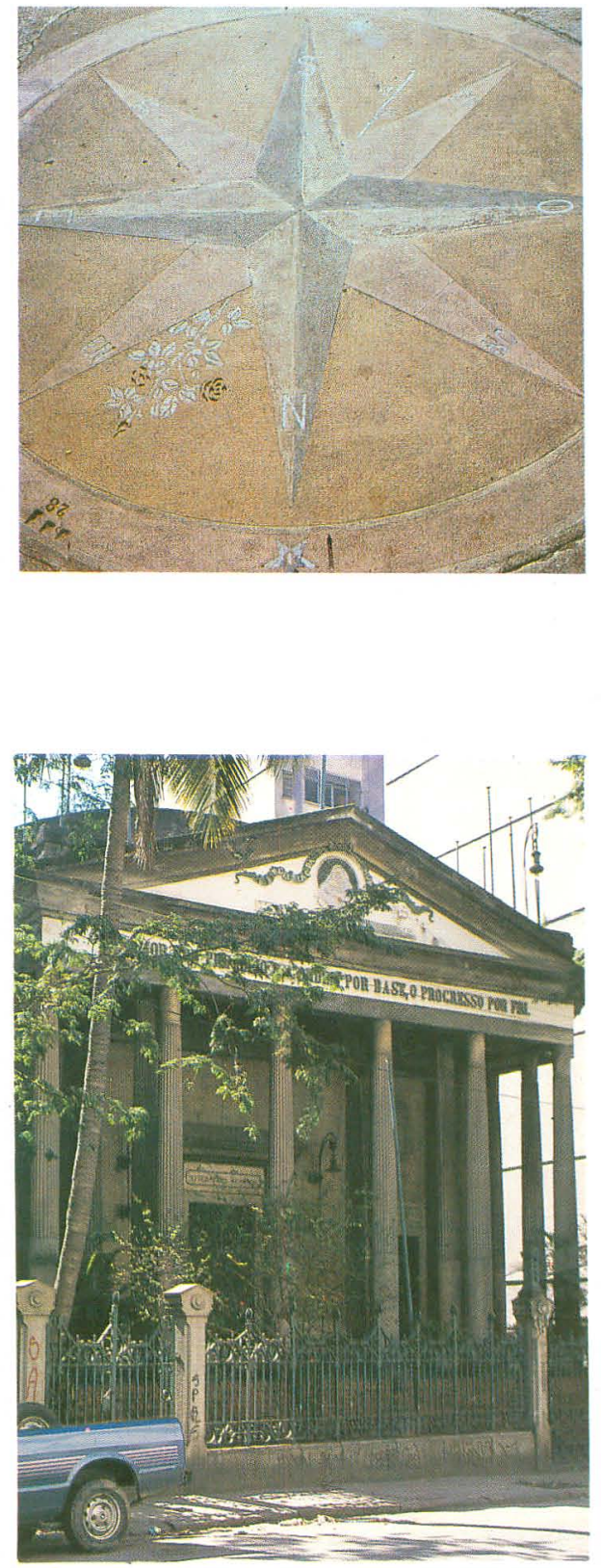

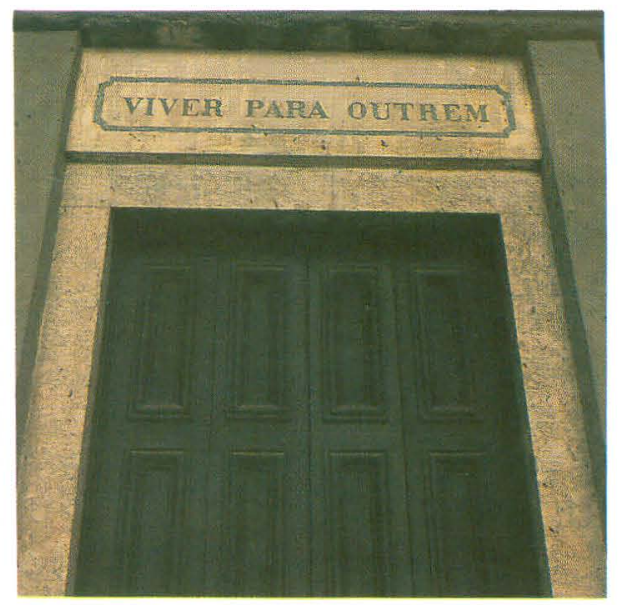

Auguste Comte recomendou que os templos positivistas tivessem sua fachada orientada para a cidade de Paris. Como as posturas municipais não permitiram tal liberdade, desenhou-se no chão do átrio uma rosa-dos-ventos com um ramo de flores indicando a posição da meca positivista.

Acima da porta que dá para o interior, gravado em pedra, um dos muitos lemas positivistas. 

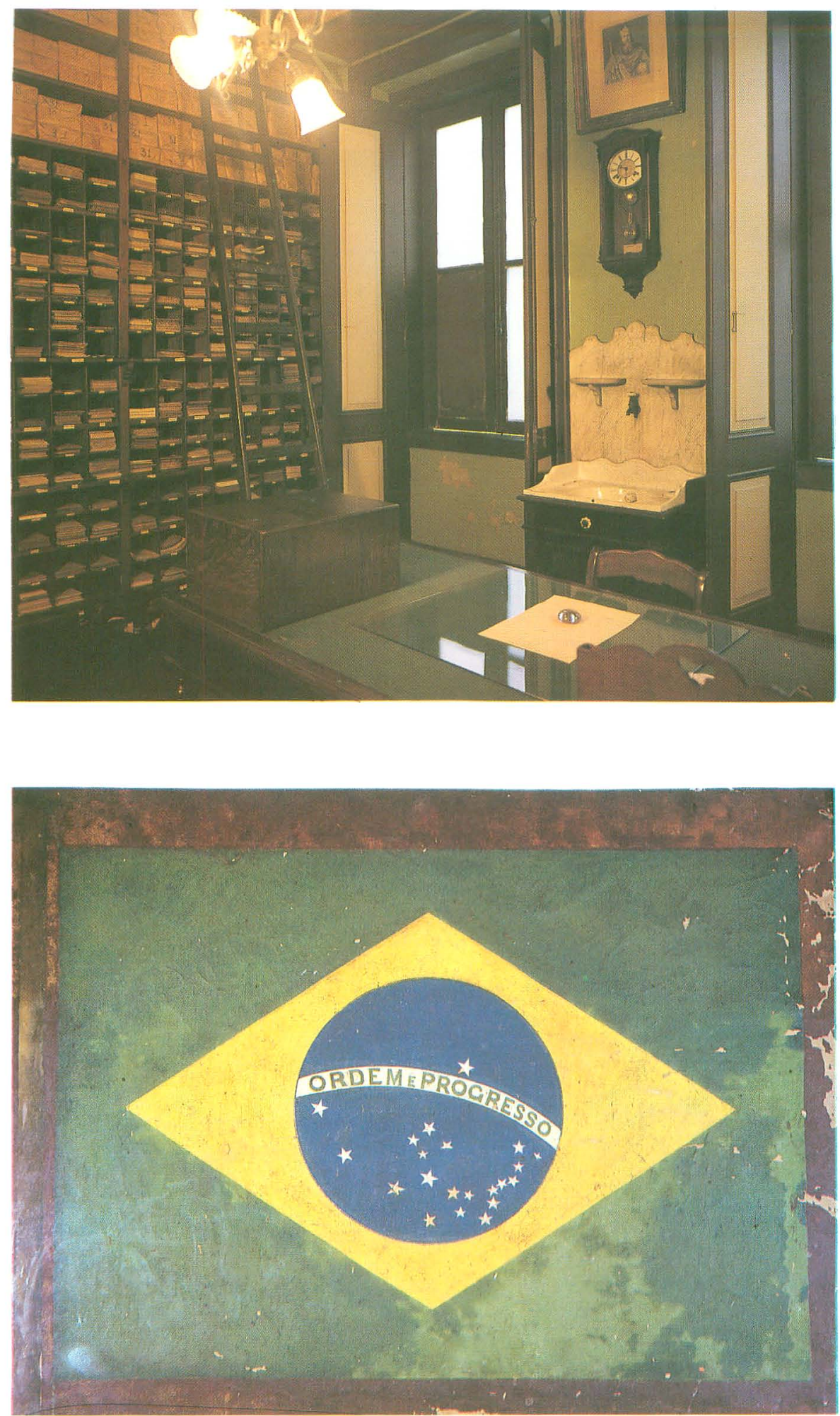

Entrando-se no templo, tem-se, à direita, a sala das publicações. Mais de 250 livretos, escritos em ortografia própria, encontram-se à disposição do público, atualmente escasso - hoje em dia os adeptos da Igreja Positivista não chegam a vinte.
Do lado esquerdo, uma sala de dimensões idênticas guarda alguns retratos de positivistas famosos (entre eles, Toussaint L'Ouverture), um molde em gesso da figura de Clotilde de Vaux e o desenho original da bandeira do Brasil, de autoria de Teixeira Mendes. 

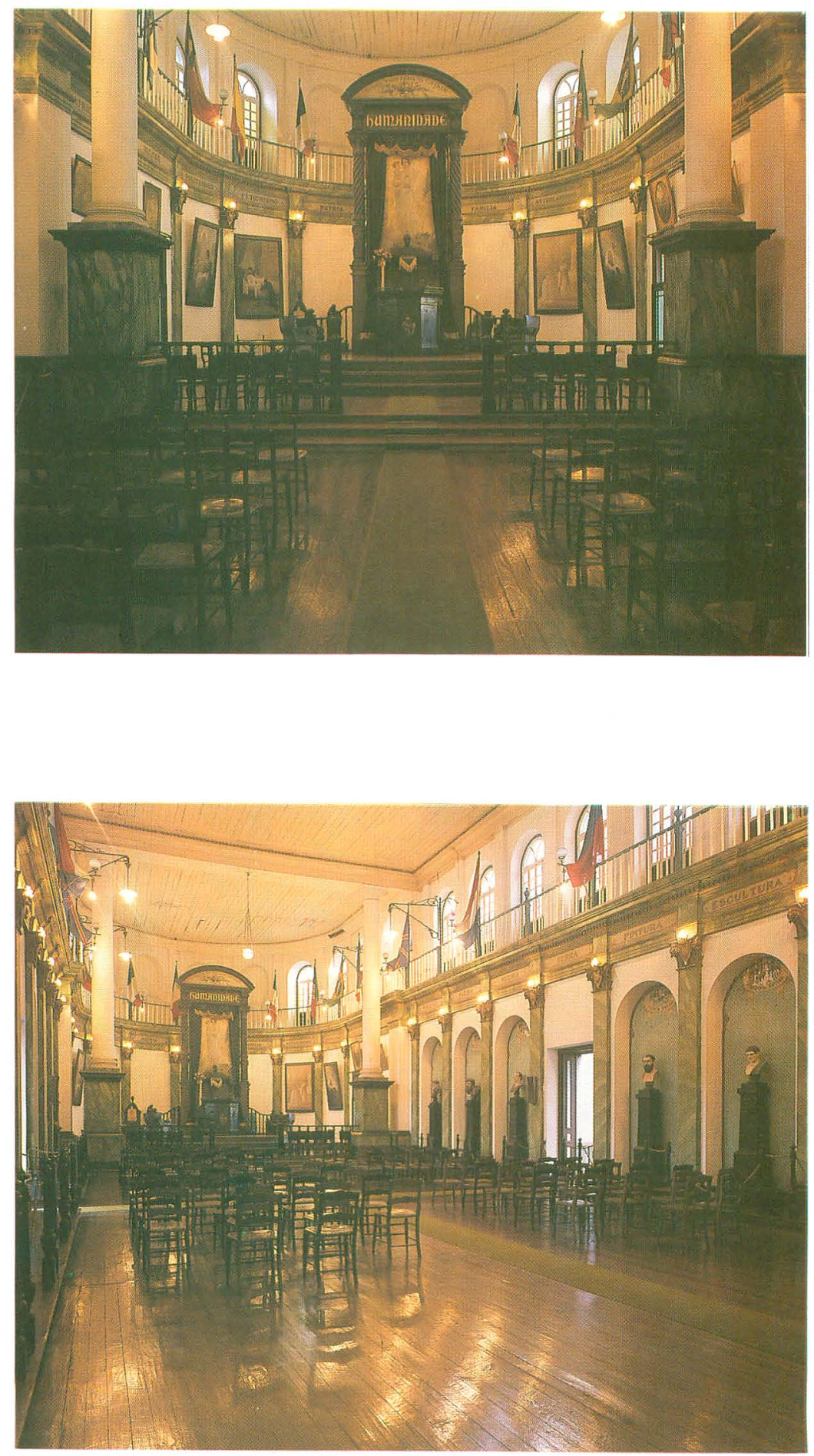

Salão principal. Ao fundo, o altar, encimado pelo busto de Augusto Comte. A exigência de ordem aparece na obsessiva arrumação das cadeiras. 

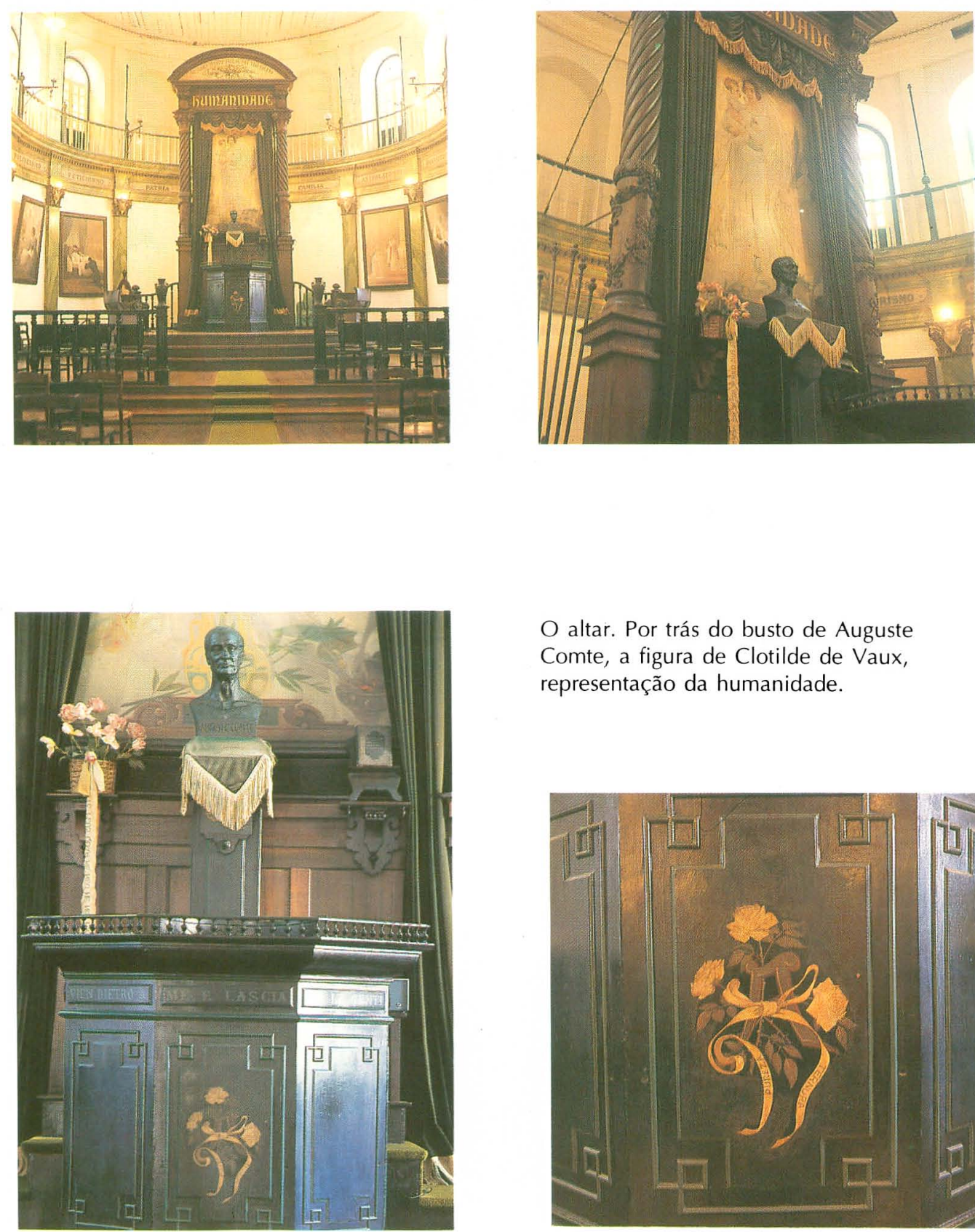

O altar. Por trás do busto de Auguste Comte, a figura de Clotilde de Vaux, representação da humanidade.

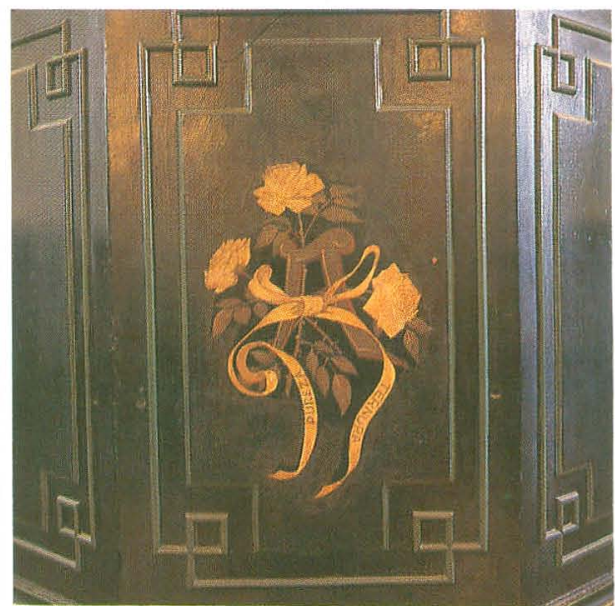




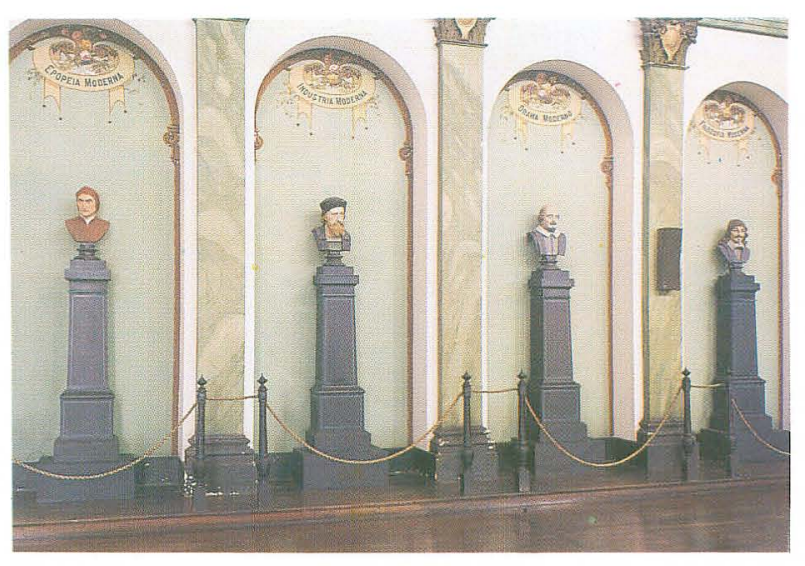

Nas paredes laterais, nichos com os 'chefes do mês', figuras proeminentes que representam campos da atividade humana, períodos históricos etc.

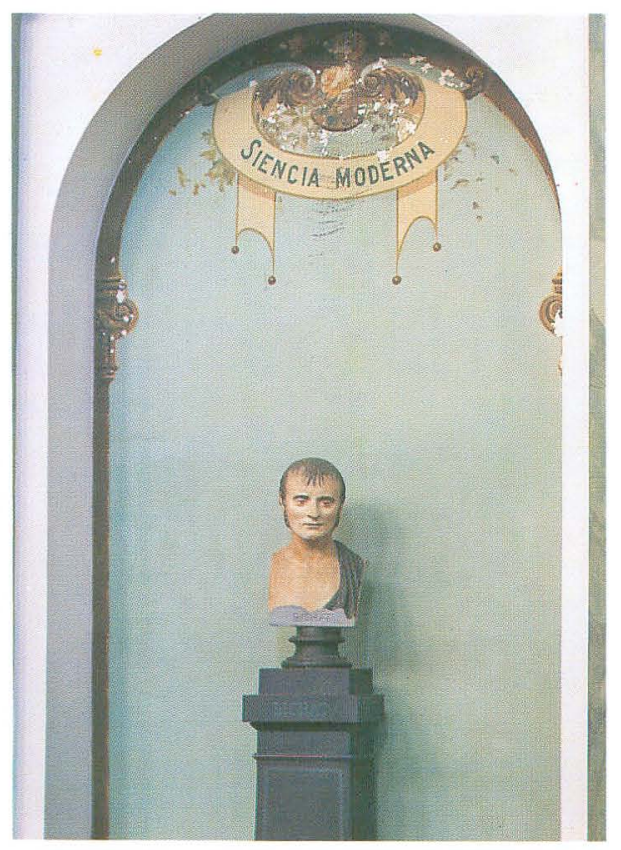

A "Siencia moderna" (observe-se a grafia) é representada por Bichat.

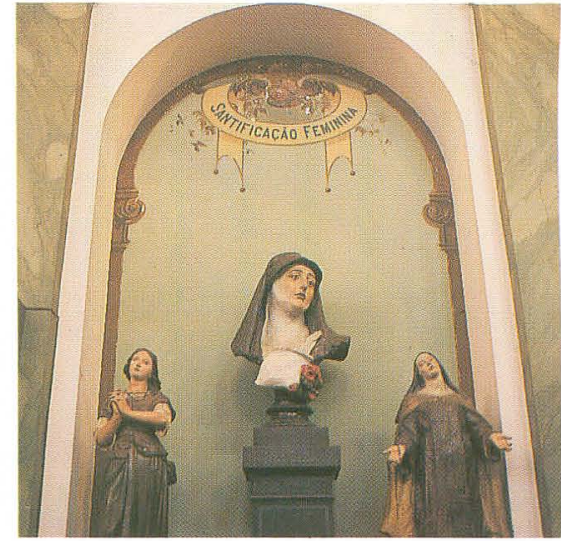

A especial deferência positivista com a mulher pode ser vista no nicho que representa a 'santificação feminina': único caso de presença de mais de uma figura, três mulheres aí estão.

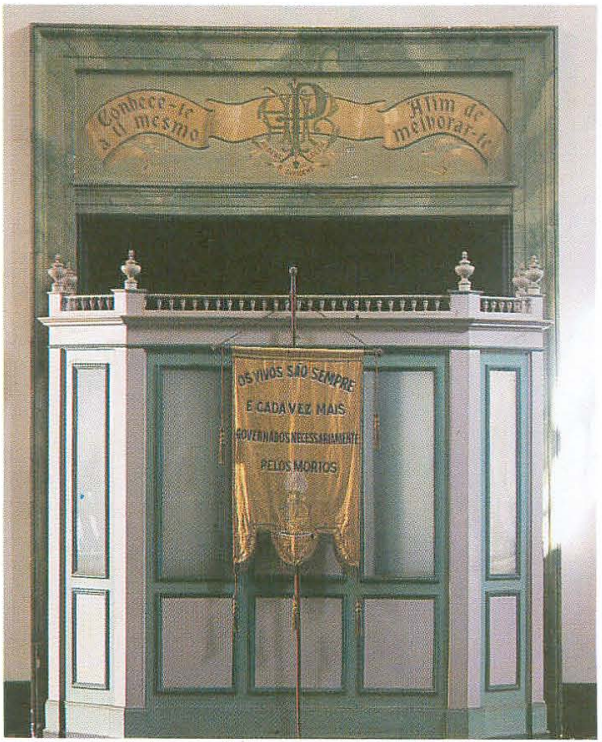

Recostado no paravento, um dos muitos estandartes que ornamentam o salão. 

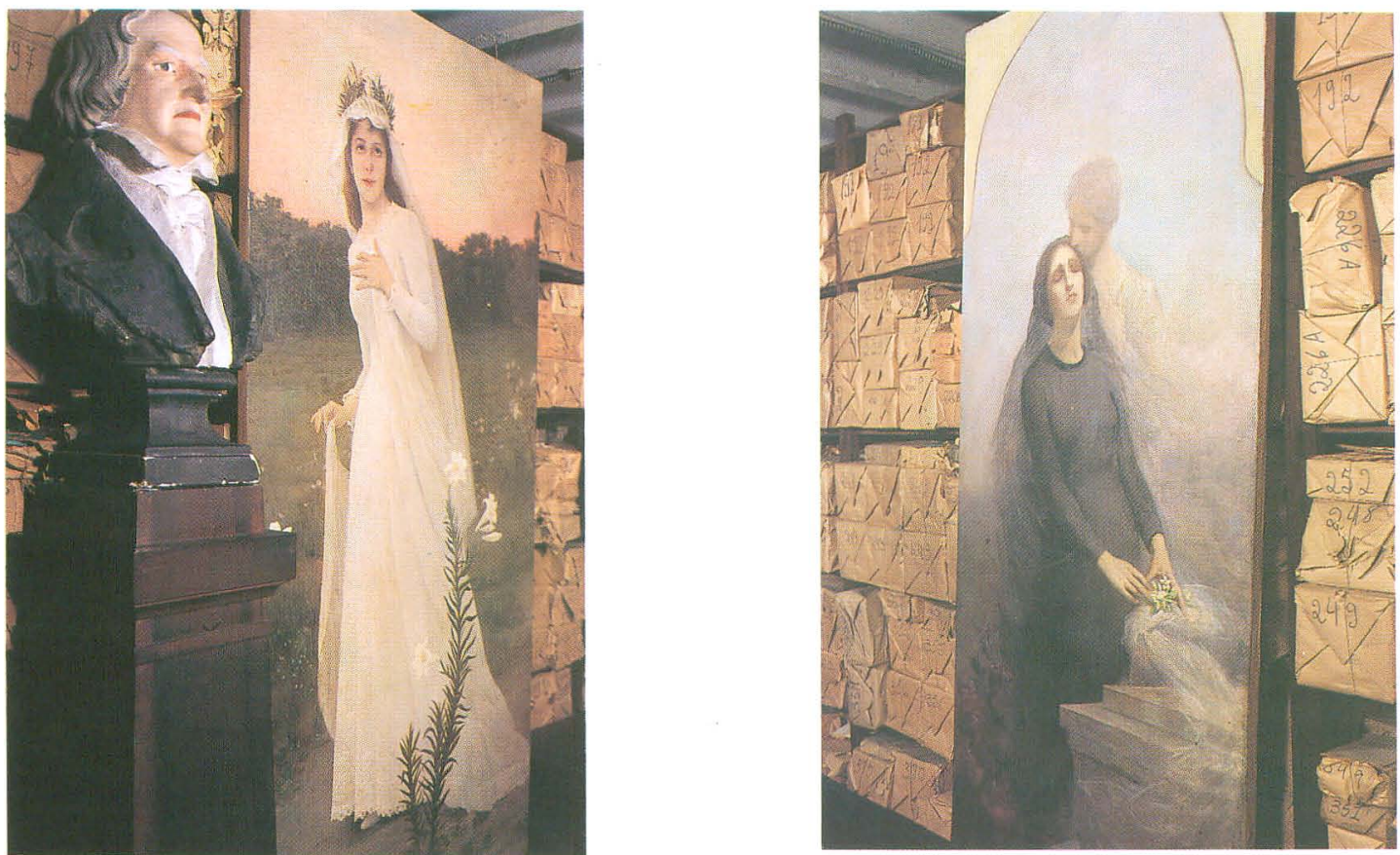

Clotilde, sempre. Duas telas, recostadas nas estantes abarrotadas de livretos não distribuídos.

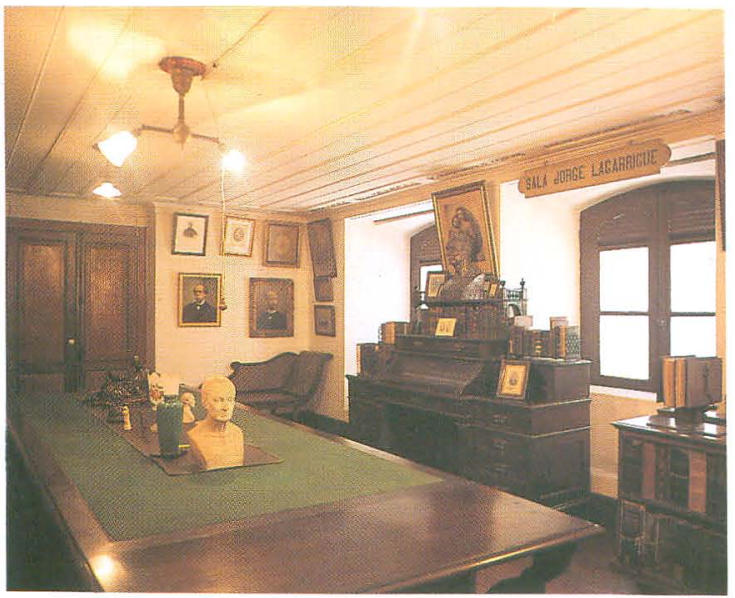

Rés-do-chão. Sala de reuniões do Conselho, com móveis preciosos.

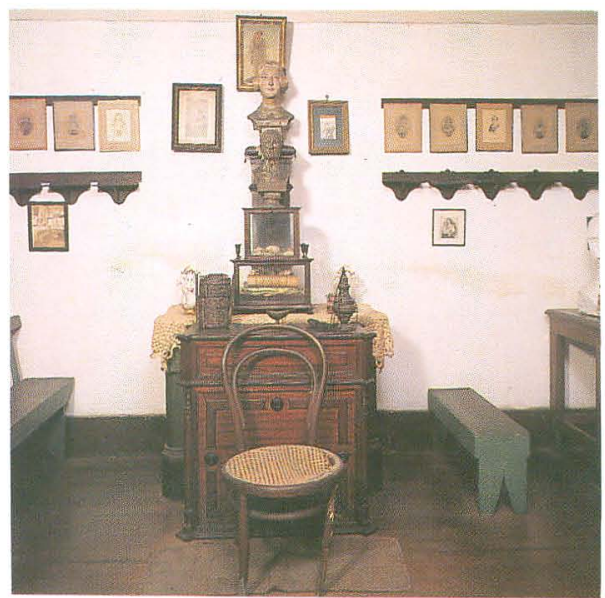

Altar e objetos votivos que pertenceram a Teixeira Mendes, em torno dos quais ele costumava reunir a família para orar e refletir. 